Laboratorio de Arte,4-1991 http://dx.doi.org/10.12795/LA.1991.i04.22

\title{
PROYECTO DE REJAS PARA LA PARROQUIA DE SAN MIGUEL DE MORON DE LA FRONTERA
}

\author{
por Manuel Clavijo Andújar
}

El arte de la rejería constituye durante el siglo XVIII un importante capítulo en nuestra región dentro de la tónica general de declive que sufre éste en los diferentes reinos de las Españas. La llegada de la nueva dinastía borbónica sólo logra introducir ciertas formas decorativas traídas de su país de origen; tanto en el ámbito de la corte como en las obras que patrocina la corona y el estado por todo el país. Prueba de ello, son las intervenciones de gusto academicista del ingeniero militar Van der Bocht en la Capilla Real hispalense.

Frente a esta política estatal de base Ilustrada, la organización gremial pugna por impulsar una tendencia que refleja el gusto popular tardobarroco, anclado en la raíz más ancestral de las tradiciones de la forja hispana. Era imposible omitir la intensidad plástica y la voluptuosa expresividad que artistas de la talla de Sebastián Conde, José Cordero, Francisco de la Chica o Pedro Muñoz Herrera implantaron en cerramientos de capillas, balanzas y cruces que delimitaban collaciones o recordaban acontecimientos luctuosos.

Junto a éstas y bajo el todavía imperante espíritu gremial, ciertas familias logran mantener la calidad del trabajo férreo combinada con el lenguaje ornamental utilizado. Una de ellas es la compuesta por los miembros de la estirpe de los Ríos, naturales de Marchena, constituyéndose así en un foco de irradiación provincial comparable a núcleos como Ronda, Jerez y Arcos de la Frontera en sus respectivas áreas de influencia. 
Las escasas noticias que hacen referencia a sus labores ponen de relieve la importancia que supone la aparición de documentación que ayude a dilucidar las labores de esta dinastía de artífices. Por ello, es fundamental consignar los datos extraídos para conocer algo más la figura de Juan de los Ríos Vallejo, sobre el cual se centran los Autos localizados para el encargo, contratación y posterior reforma de dos rejas para los arcos colaterales al Presbiterio de la Parroquia del Señor San Miguel de Morón de la Frontera. Estos se fechan en el año de 1780, mientras que el anexo de reformas se realiza en 1782. Con estas piezas férreas se sustituían dos canceles de madera que cerraban este amplio espacio, colocando los nuevos de metal en su lugar, sobre bara o pedestal de piedra encarnada del país de una vara de alto ${ }^{1}$ que serviría de pedestal o base al cuerpo de cada reja. Su costo se acordó en 1.000 ducados, sobre los cuales se hace saber que tienen tan bajo costo debido a la cercanía entre ambas ciudades vecinas, incluyendo el precio del transporte y la colocación en el lugar acordado.

Toda la obra sería costeada con el fruto de las cuentas del patronato fundado por el Licenciado Juan López Mercado, tomadas por el presbítero Don Pedro Heredia -vicebeneficiado más antiguo de esta iglesia- y administradas por el vicario Don Francisco Guizado y Angulo, que ascendían a casi 40.000 reales, al sumar a los 24.232 reales y 10 maravedies el fruto de la venta de 221 arrobas de aceite; respetando así la voluntad del patrón, que quiso se destinaran a mejoras del primer templo de la villa aruncitana.

La importancia del documento radica en su extensión y exhaustividad, que lleva consigo el poder determinar muchas de las intervenciones personales de este maestro cerrajero que habitaba las casas principales de su morada "situadas en la Plasuela de la calle San Francisco, antes llamada de Albarrasín que hasen frente a la Rexa de la ventana de la Sacristia del combento de San Francisco y lindan por una parte con casas de Don Francisco Joseph de Vera, Presvitero, y por otra con casas de los herederos de Doña María Espinosa" ${ }^{2}$ en la villa sede del ducado de Arcos.

Pero de todo ello, son quizás aquellas noticias que hacen referencia a ciertas pinceladas de su formación y evolución, las que nos acercan al artista en cuestión, a través de una relación de piezas presentadas a modo de curriculum vitae, y que atestiguan su calidad y fama, "como son la reja del Coro de la Iglesia de San Juan (Marchena), que es la principal de dicha villa a que le ayudó su Padre, a la reja de la Capilla Mayor de la misma Iglesia de San Juan que la practicó ha poco tiempo hizo para el Sagrario de la Casa Grande de Nuestro Padre San

1. Autos de Don Francisco Guizado. Mandato del Señor Visitador. Año 1780. Leg. 1487. Fol. 2 Vto. Sección Justicia. Subsección Ordinarios. A.G.A.S.

2. Ob. cit. Escritura del contrato. 6-IX-1780. Leg. 1487. Fol. 13 Vto. Sección Justicia. Subsección Ordinarios. A.G.A.S. 
Francisco (de Sevilla) donde ay un religioso selebre Maestro de este oficio y por auer salido tan a satisfacción de la Comunidad le añadieron de regalo a mas del presio en que se ajustó sien ducados" 3 .

El ya citado cerramiento del Coro de San Juan, parece ser obra de juventud en la cual se concentran las enseñanzas familiares en un barroco exhuberante caracterizado por el abigarramiento decorativo de gran sentido plástico y pictórico. La rotundidad de sus formas, expresadas en una espléndida labor calada y en el desarrollo de los balaustres, convierten este espacio en un joyel digno del deslumbrante conjunto coral que encierra. En esta reja se añade a la crestería decoración antropomórfica que engloba en su parte central un medallón con aplicaciones de chapa recortada que será el punto de partida para la decoración de las dos rejas destinadas a Morón. El tema utilizado será la tiara con las llaves, símbolo de la Cátedra de San Pedro; iconografía muy sugerente en la que se vincula el tema del Príncipe de los Apóstoles como Primer Pontífice al Papa reinante del momento; muy dentro de los dictámenes contrarreformistas, ya tan lejanos.

Por el contrario, en la segunda se nos muestra ya dentro de una línea caracterizada por una mayor claridad compositiva al aislar los valores barrocos en la crestería, o contenida dentro de estrechas fajas horizontales que enmarcan en cuerpo de balaustres sin romper la armonía de ritmos verticales. De esta manera la tensión entre formas contrapuestas crean un equilibrio que sirve de contrapunto a la hábil labor de forja de los roleos que se rematan con flores doradas de chapa recortada. Justo dentro de esta tendencia se encuentran las dos rejas que flanquean lateralmente el presbiterio de San Miguel de Morón, en las que se logran el punto de suntuosidad y apariencia tan ansiado por el barroco tardío, combinado con la delicadeza y sutil cromatismo de las notas rococó y la limpieza ornamental del incipiente academicismo (figs. 1 y 2). Fórmulas equivalentes se aprecian en otras obras que realizan estos artistas de Marchena, como bien queda constatado en las dejadas en las villas de Paradas, Estepa o Arahal.

De la misma forma que en la reja del altar mayor de San Juan de Marchena, en el diseño moronés, parece que la solución más airosa para salvar el problema de la falta de altura es el añadir un cuerpo de balaustres que equivale a un tercio del cuerpo principal colocado sobre la cornisa, siendo ésta la necesidad que se plantea ya el 30 de enero de 1782 para salvar el error de medición en que se incurrió al ser enviadas para la realización del diseño inicial.

" $Y$ no haviendo adbertido entonses que la altura de dos baras y media poco mas o menos no era correspondiente a el claro del Arco que tiene Quasi siete varas de ancho ni tampoco lo era el Alto de dicho Arco que tendra quinse o dies $y$ seis baras Es visto que dichas rejas quedaran muy bajas, ymperfectas y sin

3. Ob. cit. Elección del Maestro Rejero... F. 5. R. 
proporción a lo largo y a lo ancho de dicho Arco. Para remedio de lo qual dise dicho Maestro Ríos que es nesesario ponerle otro Segundo Cuerpo de Balaustres sobre el primero de una Bara de alto y ensima la Coronación con que quedaran con mas proporción y dezencia lo que se puede haser aora a menos costa por no estar unido a los Balaustres con la coronación, y que si se quisiese después de añadir este Segundo Cuerpo, sería menester desmontar y desbaratar las rejas, lo que tendría mucha mas costa" 4.

Para ello, realizó el reconocimiento de los bocetos y de las plantillas de hierro a utilizar el maestro herrero Dionisio Rodríguez de Zepeda, vecino de Sevilla, el 18 de enero de 1782, que corrobora la necesidad ya mencionada del añadido "para mayor vista y Custodia, siendo su colocación sobre el friso de la Rexa y sobre él se sentará la Cornisa para que Resiva su Coronación" "5 quedando tasados "cada paño de 7 varas que pesará de 22 a 24 arrobas aunque según el grueso que tenga la Rexa podrá tener en su proporción alguna corta diferencia de dos o tres arrobas mas o menos que por 3 Reales de Vellon cada libra monta cada paño de los dichos de mil y seyssientos a mil ochocientos Reales" ${ }^{6}$ variando el inicial dictamen realizado el 25 de agosto de 1780 por el maestro Francisco Nebrera.

Con esta obra de Juan de los Ríos se marca la lenta transición entre el último Barroco -estilo en el que como hemos visto se forma- y la clarificación de esquemas que lleva implícito el Academicismo ya imperante, que como a todas las órbitas provinciales llega con cierto retraso, y viene dado por la influencia de la clientela que costeaba las obras de sus patronazgos.

Así, el Arte del Fuego logrará el decisivo paso para alcanzar el ya cercano siglo XIX en el que las obras de carácter sacro quedarán definitivamente desplazadas por las de tipo civil, que absorberán las labores de los ya escasos artífices. Serán los cierros, cancelas y balcones de casas señoriales -ya regentadas por esa burguesía provinciana enriquecida- las que les ayudarán a subsistir frente a la irrupción avasalladora de los procesos industriales, aplicados a los procedimientos técnicos. Todo ello propiciará un largo letargo hasta que el movimiento Arts \& Crafts y su influencia en el Modernismo vuelva a rescatar el espíritu artesanal del artista; perdurable siempre en la recia solemnidad con que el arte férreo dota a la arquitectura.

4. Ob. cit. Dictamen para la reforma de las piezas... F. 18. R.

5. Ob. cit. Dictamen del Maestro Herrero Dionisio Rodríguez de Zepeda... F. 2 vto.

6. Ob. cit. Fol. 6. 


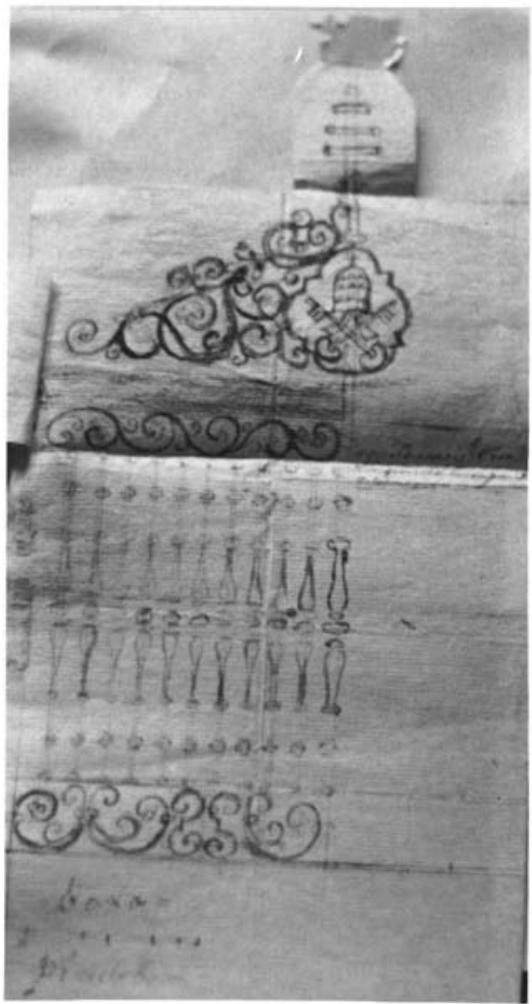

1. Diseño de la reja lateral para la Capilla Mayor del templo de San Miguel de Morón de la Frontera, obra de Juan de los Rios Vallejo. 

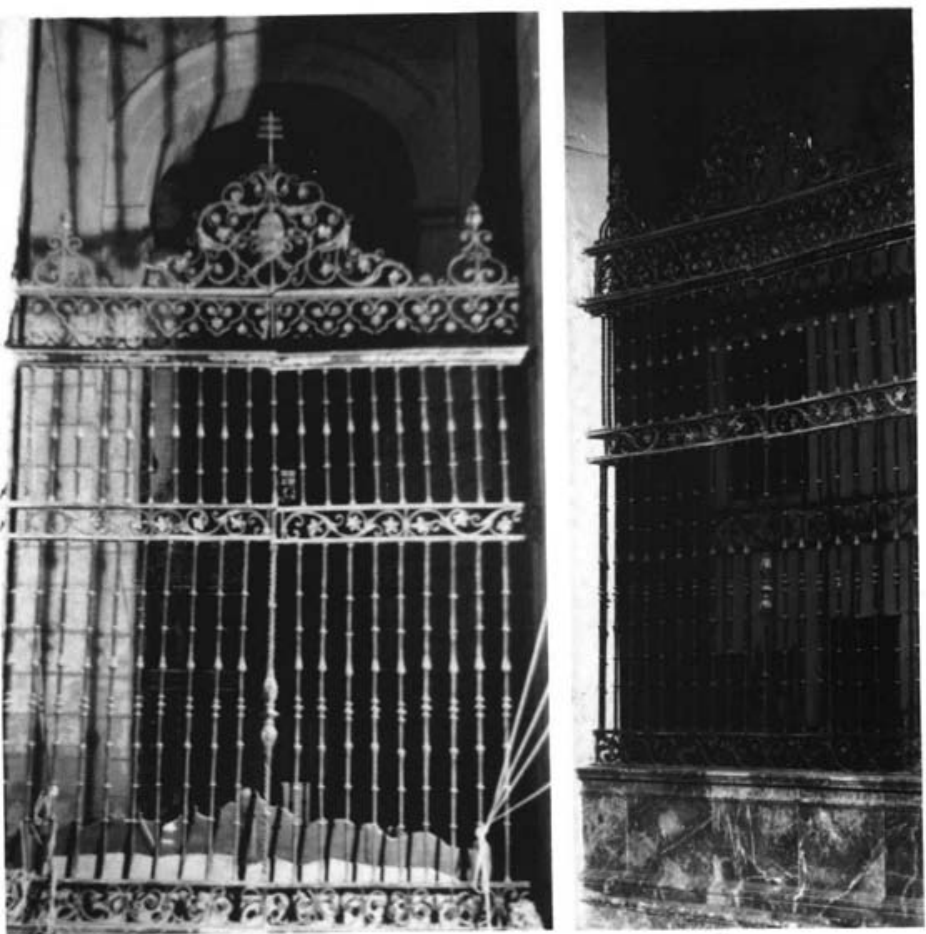

2. Reja lateral de la Capilla Mayor del templo de San Miguel de Morón de la Frontera, ohre de Juan de los Ríos Vallejo. 